\title{
Effect of entrepreneurial networks on small firm performance in Kamrup, a district of Assam
}

\author{
Mandakini Das ${ }^{1 *}$ and Nivedita Goswami ${ }^{2}$
}

\author{
* Correspondence: \\ mandakinidas05@gmail.com \\ ${ }^{1}$ Research Scholar, Department of \\ Economics, Gauhati University, \\ Guwahati, Assam, India \\ Full list of author information is \\ available at the end of the article
}

\begin{abstract}
The study is an attempt to examine the potential impact of entrepreneurial networks on small firm performance with the help of primary data.

Dimensions of entrepreneurial networks used in this study are network structure (size, density and centrality) and network types (competitive and supportive). The population of the study consists of small firms of Kamrup a district of Assam. The analysis is done with the help of hierarchical regression model. The results reveal that network density and centrality have a positive impact on firm performance. However competitive and supportive network is not significant. The idea is to understand how small firm performances are important for policy makers, business advisors and other stakeholders to serve the business sector in a better way.

Keywords: Entrepreneurial networks, Small firms, Performance, Assam
\end{abstract}

\section{Background}

The term "entrepreneurial network" refers to entrepreneurs, who are organized, formally or informally, with the aim to increase the efficiency of the members' business activities. ${ }^{1}$ According to Birley, Cromie \& Myers, (1991) Networking is an activity by which entrepreneurs obtain information about new entrepreneurial ideas. In traditional economic theory, the main factors of production are land, labour, capital and entrepreneurship. Bhattacharyya and Ahmad (2010) state that apart from land, labour, capital and entrepreneurship, any entrepreneurial initiative involves competent use of networks which could be used for generating business or increasing the effectiveness in business processes. Many scholars have asserted that various aspects of networks can be beneficial in a firm's environment (Gulati, Nohria \& Zaheer, 2000); (Hite \& Hesterly, 2001); (Johannisson, Alexanderson, Nowicki \& Senneseth, 1994). According to Gulati et al. (2000) strategic networks give a firm the access to resources, markets, information and technologies. They noted that the conduct and performance of firms can be better understood by understanding the network of relationships in which firms are placed. For instance, those entrepreneurs who use their suppliers and customers as sources of support during the gestation period are likely to grow faster (Capelleras \& Rabetino, 2008). From earlier studies it can be said that networks are a significant factor throughout the entire process of entrepreneurship development. Furthermore,

(c) The Author(s). 2019 Open Access This article is distributed under the terms of the Creative Commons Attribution 4.0 International License (http://creativecommons.org/licenses/by/4.0/), which permits unrestricted use, distribution, and reproduction in any medium, provided you give appropriate credit to the original author(s) and the source, provide a link to the Creative Commons license, and indicate if changes were made. 
this statement is more related with small scale industries because small firms are not able to attain their goal on their own. To do so, small firms ${ }^{2}$ need resources and support from outsiders such as other firms, supporting institutions, as well as relatives and friends.

Many studies (Donckels \& Lambrecht 1995; Hansen and Wernerfelt, 1989) have argued that the success of small firms is dependent on other people who can provide them the required support to improve their performance. The support networks allow entrepreneurs to identify opportunities and resources faster. This makes networks are extremely valuable to the small enterprises for accessing resources in the market. So the entire focus of this research is on small firms.

The idea is to justify that small firms and business development depend on external factors due to lack of resources in the market. The entrepreneurial networks also minimize transaction costs and the risk of failure. Such constructive aspects of networks for small firms demand greater empirical evidence and the present study is an attempt in that direction. This would enable us in bridging the gap in our understanding of how entrepreneurial networks are formed. Also, there is indeed a gap in knowledge in our understanding of how entrepreneurial networks operate.

In the context of Assam, the entrepreneurship development of the state has been extensively studied but there have not been any known attempts to analyze the issues related to entrepreneurial networks and their importance in the entrepreneurial firm performances. In view of this perceived gap in research, the present study has been taken up where the focus is on the networking and firm performances.

This study focuses on small firms of Kamrup district of Assam engaged in manufacturing enterprises. In the entire north-eastern region of India, Assam alone accounts for roughly $70 \%$ of the industrial units of the region ${ }^{3}$ and within Assam; Kamrup district has the highest numbers of small enterprises followed by Dibrugarh, Sivsagar and Nagaon (2016-17) and hence the district is selected for the study. The Industrial sector of Assam has several constituent parts, viz, Mining and Quarrying, Manufacturing, Electricity, Gas, Water supply \& other Utility services and Construction sectors. According to latest Economic Survey, Assam, 2016-17, the encouraging growth of the Industry sector in 2016-16 could be attributed to the performance of the manufacturing sector which grew by $9.41 \%$ compared to the growth of $5.33 \%$ in the previous year 2014-15. An important component of the Industrial sector is the Small Scale Industries (SSI) or Micro Small and Medium Enterprise (MSME) sector. The overall performance of the Industry sector is encouraging in 2015-2016 compared to previous years. ${ }^{4}$ In Assam, there were a total of 43,332 SSI/MSME units which provided employment to 2.49 lakh persons till the end of March 2016. Keeping in view the significant role of manufacturing sector, this study looks at the performance of small enterprises involved in the manufacturing sector and located at Kamrup.

The rest of the paper is organised in the following sections. Section 2 discusses the theoretical understandings of the concepts of networks and their impact on firm performance. The empirical review has also done in this study to understand the relationship between networks and firm performance. Section 3 presents the main objective of this study. Section 4 and 5 explains the hypotheses and methodology used for this study. Section 6 analyses the results and discussions and lastly section 7 and 8 concludes along with suggestions and future scope. 


\section{Literature review}

The aim of this section is to examine the theoretical concepts related to networks and their impact on firm performance and present a comprehensive analysis of empirical literature that is associated with this topic. Hence, the literature review of this research has been thematically divided into the following sections.

\section{Entrepreneurial networks and firm performance}

Aldrich and Zimmer (1986), in their research have stated that, "entrepreneurial networks" are an entrepreneur's personal relationships with his/her 'external actors or outsiders'. Adding support to the above claim, (Birley et al., 1991) and (Dubini \& Aldrich, 1991) have stated that network has a long-term contact between small business owners and external actors ${ }^{5}$ in order to get information, moral support and help with other resources.

In the present study, the entrepreneur's personal relationships have been taken into consideration because the 'entrepreneur' is the main composer in a small business firm. The various theoretical linkages outlined in the literature enable us to develop an empirical research model that shows the most probable relationship among the variables namely firm performance and networks. Figure $1^{6}$ presents the empirical research model of entrepreneurial networks and firm performance.

\section{Measuring firm performance}

Performance is a commonly used concept in various fields. Usually, performance is a measure of how well a process can achieves its purpose. Measuring performance is a multi-dimensional concept. Traditional performances were too historical and regressive

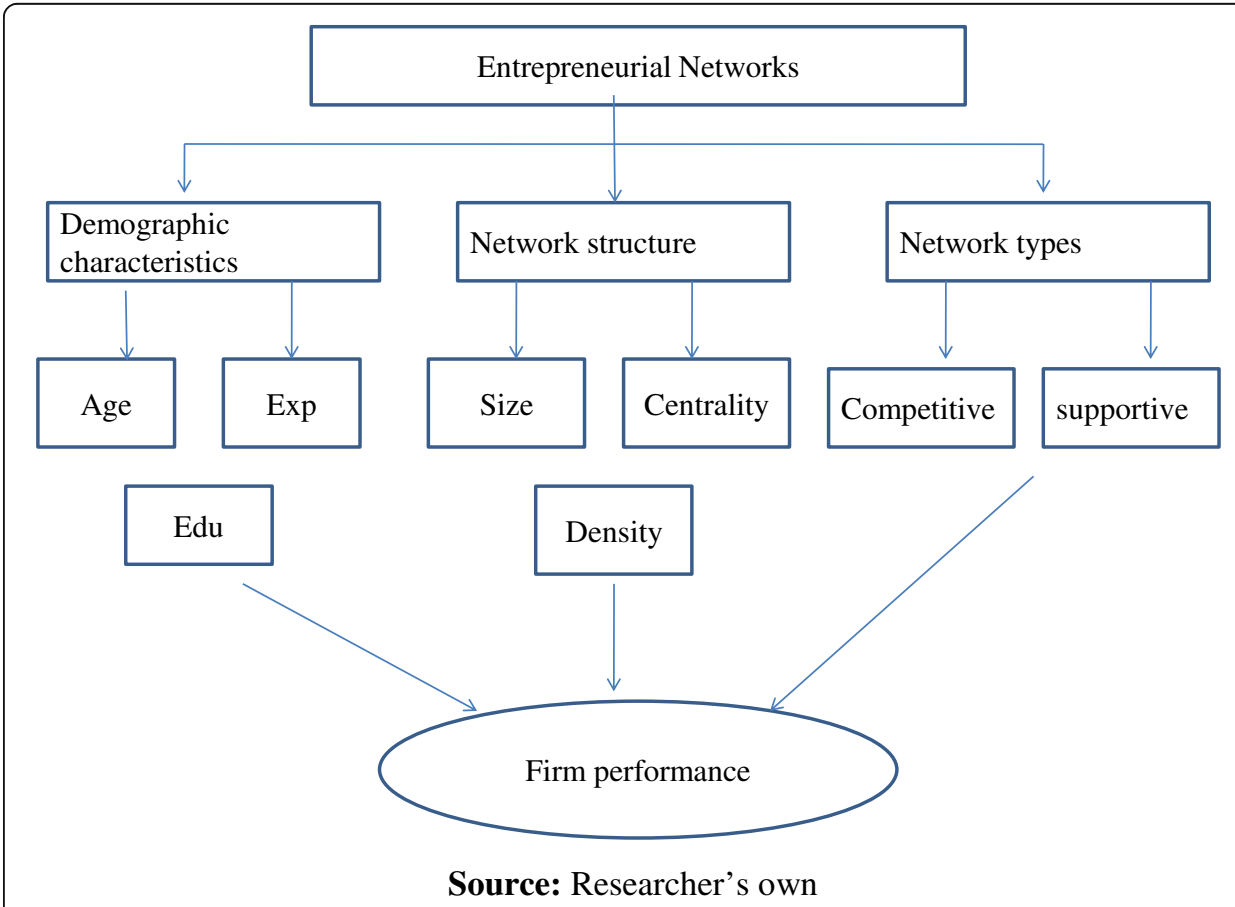

Fig. 1 Entrepreneurial networks and firm performance: An empirical research model 
(Ittner, Larcher \& Meyer, 2003) as they do not link subjective performances to objective numbers. Objective and an non-objective measures must be associated to fit within a strategic framework (Drucker, 1990; Mcnair and Mosconi, 1987). The empirical literature reports a high diversity of performance indicators (Combs, Crook \& Shook, 2005) and the common distinctions are objective and subjective measures.

Subjective measures allow capturing of information, which is often hidden in the explicit financial measures (Ittner et al., 2003). In their study, Richard, Devinney, Yip and Gerry (2009) have suggested some common measures of subjective performance such as product designs, process quality, corporate social performance, reputation, productivity and innovations. The empirical research in the field indicates a strong relation between subjective and objective measures of performance (Dawes, 1999; Hoffman et al., 1991). Banker, Potter and Srinivasan (2000) suggested that subjective measures were better predictors of long-term objective measures and delivered additional information that was not available through past objective measures. Accordingly the present study has used only subjective measures of performance.

\section{Network structure and enterprise performance}

The structure of an entrepreneurial network usually consists of the size of the network, density of the network and network centrality. In this study, network size means the number of contacts an entrepreneur has. The greater the number of contacts the entrepreneur is able to form better is the possibility of him/her gaining access information and different types of resources (Batjargal, 2000; Burt 2000). According to Li and Zhang (2007) entrepreneurial network size has a positive relation with sales growth. Hanneman and Riddle (2005), stated that the density of the network refers to the number of relationships the entrepreneur has within the network as compared to the total possible size of the network. A thick web of social ties exists in a community-based cluster as everyone is related to every entrepreneur either directly or indirectly through friendships or kinship, which increases the possibility of high density. The centrality measure of network signifies how well connected an her overall network/her overall network (Farina, 2008). Centrality also indicates an entrepreneur's close ties with network partners in terms of the frequency of quickness, superiority, transaction and control of resources and information.. According to (Farina, 2008) study, a positive relationship has been found between centrality and enterprise performance. However; Batjargal (2000), in his study shows a negative impact of network on performance.

\section{Network types and enterprise performance}

The network types of an entrepreneur are generally composed of the competitive network and supportive network. (Das, 1996) in his study said that competition increases certain unhealthy practices such as copying designs/patterns/trademarks, obtaining information, and price competition. However, concentration of suppliers, buyers and entrepreneurs at one place creates a potential site for intervention by supportive institutions such as government and non-government agencies, financial institutions, etc.

Supportive networks are made up of trade unions, lawyers, banks, accountants, cooperatives and government agencies, research and training institutions, which have been put up to help enterprise within a cluster (Prajapati, \& Biswas, 2011). 


\section{Demographic characteristics and firm performance}

The demographic characteristics of people also shape their behavioural patterns towards entrepreneurship. According to Li and Zhang (2007) the role of demographic characteristics such as age, gender, religion, experience, background and education of entrepreneurs towards their entrepreneurial behaviours and firm's performance matter a lot.

Instead of taking all the components of demographic characteristics into account, this study explores age, gender, experience and education.

\section{Gap areas as identified from literature review}

The following gaps have been identified based on the review of literature:

There have been many studies on entrepreneurial networks affecting firm performances, that have been done in the West and so its impact needs to be examined and applied in the Indian context, as well.

In the context of Assam, while entrepreneurship development of the state has been extensively studied, most of the previous studies about entrepreneurship focus on the weaknesses and problems of SMEs, financial issues, government agencies' support etc. But no known attempts have been made to analyze the issues related to entrepreneurial networks and their importance in the entrepreneurial process. Therefore, the findings of this study will provide valuable information associated with entrepreneurial network to existing and new SMEs entrepreneurs in Assam.

\section{Objective}

The objective of this study is to examine the impact of entrepreneurial networks in form of network size, network density, network centrality, competitive network and supportive network on the subjective firm performance.

\section{Hypotheses}

By drawing on the above literature and objective, below are the hypothesis formulated in this study.

Hypothesis 1A: Network size has an impact on subjective firm performance.

Hypothesis 1B: Density of the network has an impact on subjective firm performance.

Hypothesis 1C: Network centrality has an impact on subjective firm performance.

Hypothesis 2A: Competitive network has an impact on subjective firm performance.

Hypothesis 2B: Supportive network has an impact on subjective firm performance.

\section{Methodology}

\section{Sample and data}

A survey-based approach has been used to collect data from small firms operating in Kamrup. Kamrup district was selected primarily because the district has a total of 14,776 SSI units which is almost $30 \%$ of the state's total. ${ }^{7}$ Small firms of the district are based on the manufacturing sector.

In this study, the population comprises small firms operating in Kamrup district. The required information was collected through a well-structured questionnaire. This study 
used field survey research methods to provide a basic picture of the entrepreneurial network linkages and firm performance and to analyze the effects of network on the firm performance. The sample of the study was selected according to four criteria. The first criterion was that the firms were registered under District Industries and Commerce Centre (DICC), Kamrup. The second criterion was that the investment limit should be between 25 lakhs to five crores in plant and machinery (according to the definition of MSME Act, 2006). The third criterion was that the firm had a maximum of five years of establishment period in order to check their firm performance. Finally, only Kamrup metro areas were taken up in this study. A total of 35 firms were recognised as fulfilling the criteria described above.

The survey was conducted from November 2017 to December 2017 through face to face encounters with owners/managers with duration of approximately $30 \mathrm{~min}$. Of the 138 recognised firms in Kamrup Metro area, 35 managers/owners were interviewed, and consequently the response rate was $25 \%$. More units could not be covered due to the unwillingness or non-cooperative attitude of the SSI entrepreneurs as well as time constraint on the part of the researcher.

\section{Variables used in the study and their measures}

The variables used in this empirical study are: (1) Dependent variable (firm's performance); (2) Independent variables; and (3) Control variables.

1. Subjective firm performance (SFP): An eight-item, five-point, subjective performance scales were adopted from Prajapati and Biswas (2011). The items of firm performance are: sales growth, product quality, returns on assets, returns on investment, and returns on equity, employment growth, market share growth and gross profit margin. Respondents were asked to point out their opinions of the performance information. All items were measured with five point Likert-like scale ${ }^{8}$ of 1 meaning 'very poor' to 5 meaning 'excellent'. A subjective measure of performance showed good reliability (Cronbach $\alpha=0.91$ ). The variable score was obtained after combining mean of the scale measures.

2. Network size: Network size refers to the total number of contacts of an entrepreneur. It indicates to the number of ties the entrepreneur has built within the network to secure the business information and the resources. An entrepreneur's network consists of family, friends, relatives, government and bank officers, customers and supportive institutions, and suppliers of raw materials. The respondents were asked about the number of people they interact with on a regular basis, following which the size of the network was calculated by adding number of relationships in each category.

3. Network Density: The scale for density has been adapted from Prajapati and Biswas (2011) and Frazier (2000). The scale consisted six items, namely: Family/relatives, friends, suppliers of raw materials, customers, government officers, and support institutions. The density of network was measured on the basis of how much reliable information the entrepreneur shared with those people (six items). To give their opinion, the respondents were requested to mark on a five point Likert scale indicating the extent of agreement (Strongly disagree $=1$; strongly agree $=5$ ) to each of the 6 items in the scale. Density scale showed acceptable reliability (Cronbach $\alpha=0.61){ }^{9}$ 
4. Network Centrality: Measures of density adapted from Prajapati and Biswas (2011) and Frazier (2000). The scale consists of 6 items covering exchange frequency and quickness of resources and information with suppliers, family, friends, relatives' buyers and competitors. In order to give their opinion, the participants were requested to mark on a five point Likert scale $(1=$ strongly disagree; $5=$ strongly agree) on items such as 'I frequently exchange resources'. Centrality scale had moderate reliability (Cronbach $\mathrm{a}=0.65$ ).

5. Competitive network: Measures of competitive network were adapted from Prajapati and Biswas (2011). The scale consisted of five items covering copying designs/pattern by competitors, poaching of customers, poaching of employees, price competition and obtaining information. Similarly, the participants were requested to indicate their extent of competition on a five-point Likert scale. Competitive network scale was (Cronbach $\alpha=0.77$ ), demonstrating high reliability.

6. Supportive network: Measures of competitive network were adapted from Prajapati and Biswas (2011). The scale consisted of four items covering: 'NGOs were supportive', 'Government departments were supportive', 'I frequently utilise services of banks for finance', and 'Institutions/organisations were supportive'. The participants responded on a five-point Likert scale indicating the extent of agreement ( $1=$ Strongly Disagree; $5=$ Strongly Agree). Supportive network scale showed high reliability (Cronbach $\alpha=0.76$ ).

7. Control variables: From the existing literature Li and Zhang (2007), four control variables were taken, namely, gender, age, experience and education. The previous literature indicates that these variables have the possibility to influence the performance of a firm.

\section{Line of analysis}

In this study, correlation coefficient, mean and standard deviation of all measures were used to test the relationship of study variables. Secondly, hierarchal regression ${ }^{10}$ analysis was conducted as the main statistical method for investigating the relationship between demographic control variables and firm performance.

\section{Results and discussions}

\section{Reliability assessment}

The internal consistency and reliability of the main constructs was analysed using Cronbach's alpha. Cronbach's alpha is the most common measure of internal consistency. According to Gliem, J.A., \& Gliem, R.R (2003) while using Likert-type scales it is essential to calculate and report Cronbach's alpha coefficient for internal consistency for any scales or subscales one may be using. According to them, "The analysis of the data then must use these summated scales or subscales and not individual items." ${ }^{11}$ A full list of all constructs and corresponding Cronbach's alpha are shown on Table 1 . To test the reliability of the measures, SPSS 16 was used.

\section{Descriptive statistics and correlations among variables}

Correlation, Mean and Standard Deviations of all measures are presented in the Table 2. 
Table 1 Summary of predictor Measures

\begin{tabular}{llll}
\hline Predictor & Number of items & Scale format & Cronbach's Alpha \\
\hline SMP & 8 & $1-5$ Likert scale & 0.91 \\
Network Density & 6 & $1-5$ Likert scale & 0.61 \\
Network Centrality & 6 & $1-5$ Likert scale & 0.65 \\
Competitive network & 5 & $1-5$ Likert scale & 0.77 \\
Supportive network & 4 & $1-5$ Likert scale & 0.76 \\
\hline
\end{tabular}

Source: Author's calculation from primary survey

Table 2 reveals that the age of the entrepreneur, density, network centrality, competitive network and supportive network were positively and significantly related to subjective performances, but gender, experience, education level and network size were not related to subjective firm performance.

\section{Hierarchical regression analysis}

To test the hypotheses given in section 4, this study used hierarchical regression analysis method. It is used as the main statistical procedure for examining the relationship between entrepreneurial networks and firm performance. Hierarchical regression is used when the data is organized into a tree-like structure which is shown in the research model Fig. 1. The data are stored as records which are connected to one another through links. In this study, the predictor variable and control variable is a link with each other. Therefore, sequential regression with performance as the dependent variable was tested. In the Model 1 entrepreneurs, demographic attributes such as age, gender, experience, and education were entered. In Model 2 structure of networks was entered and In Model 3 types of networks was added Accordingly, one reason to use Hierarchical regression instead of regular regressions because this method allows the researcher to separate within-group effect from between-group effect; Whereas Level 1 regression blends them together into a single coefficient (Veronika; Huta 2014). Before

Table 2 Correlation, Mean and Standard Deviation of all variables

\begin{tabular}{|c|c|c|c|c|c|c|c|c|c|c|c|}
\hline Variables & Mean & SD & 1 & 2 & 3 & 4 & 5 & 6 & 7 & 8 & 9 \\
\hline $\begin{array}{l}1 \text { Subjective } \\
\text { performance }\end{array}$ & 3.53 & 0.61 & 1 & & & & & & & & \\
\hline 2 Gender & 1.26 & .443 & .047 & 1 & & & & & & & \\
\hline 3 Age & 40.57 & 8.118 & $.438^{* * *}$ & -.173 & 1 & & & & & & \\
\hline 4 Experience & 4.20 & 0.58 & -.175 & $.363^{*}$ & $-.136^{* * *}$ & 1 & & & & & \\
\hline 5 Education & 15.85 & 8.92 & .155 & - & .671 & -.220 & 1 & & & & \\
\hline 6 Network size & 14.11 & 12.4 & .099 & $-.267^{*}$ & $.416^{* * *}$ & .025 & $.267^{*}$ & 1 & & & \\
\hline 7 Density & 3.99 & 0.48 & $.521^{* * *}$ & -.102 & $.426^{* * *}$ & -.045 & $.410^{* * *}$ & $.497^{* * *}$ & 1 & & \\
\hline 8 Centrality & 4.06 & 0.50 & $.497^{* * *}$ & -.073 & .219 & .173 & .188 & $.330^{* *}$ & $.516^{* * *}$ & 1 & \\
\hline $\begin{array}{l}9 \text { Competitive } \\
\text { network }\end{array}$ & 3.52 & 1.06 & $.283^{* *}$ & .192 & .104 & .120 & .148 & $.273^{* *}$ & .139 & $.347^{* *}$ & 1 \\
\hline $\begin{array}{l}10 \text { Supportive } \\
\text { network }\end{array}$ & 2.82 & 1.06 & $.226^{*}$ & .007 & .091 & .024 & .062 & $.562^{* * *}$ & .216 & $.238^{*}$ & $.609^{* * *}$ \\
\hline
\end{tabular}

Source: Author's calculation from primary survey

Notes: ${ }^{* *}$ Correlation is significant at the 0.01 level

** Correlation is significant at the 0.05 level, * Correlation is significant at the 0.10 level $(N=35)$ 
estimating the models, diagnostic test has been performed to detect the presence of multicollinearity. Value Inflation Factors (VIFs) ${ }^{12}$ was calculated to examine multicollinearity among predictors. The check for multicollinearity revealed that the VIFs values were within the acceptable limit. To test the impact of entrepreneurial networks and firm performance, three regression models were formulated. Dependent Variable "Y" as indicator of subjective firm performance $(S F P)$. Independent variables are $X_{n}$ as dimensions of entrepreneurial networks and firm related control variables $\left(\mathrm{X}_{1=}\right.$ Gender, $\mathrm{X}_{2}$ Age, $\mathrm{X}_{3}$ Experience, $\mathrm{X}_{4}$ Education, $\mathrm{X}_{5}$ Network size, $\mathrm{X}_{6}$ Density, $\mathrm{X}_{7}$ Centrality, $\mathrm{X}_{8}$ Competitive network, $X_{9}$ Supportive network). Therefore, the econometric models that are framed in order to capture the phenomenon are given below.

Model $1=S F P=\beta 1+\beta 2$ Gender, $+\beta 3$ Age $+\beta 4$ Experience $+\beta 5$ Education $+u$

Model $2=S F P=\beta 1+\beta 2$ Gender, $+\beta 3$ Age $+\beta 4$ Experience $+\beta 5$ Education $+\beta 6$ Network size $+\beta 7$ Density $+\beta 8$ Centrality $+u$

Model $3=$ SFP $=\beta 1+\beta 2$ Gender, $+\beta 3$ Age $+\beta 4$ Experience $+\beta 5$ Education $+\beta 6$ Network size $+\beta 7$ Density $+\beta 8$ Centrality $+\beta 9+$ Competitive network $+\beta 10$ Supportive network $+u$

Three sequential regression models were estimated. In model 1 , the effects of the demographic control variables were estimated. In model 2, the control variables and the main effects of network variables were estimated. In model 3, all variables were estimated. The results are discussed in the Table 3.

Table 3 reveals that, in model 1, entrepreneur's demographic control variables such as gender, age, experience and educational level were inserted. The multiple $\mathrm{R}^{13}$ shows a substantial correlation between the predictor variables and the dependent variable $\operatorname{SFP}(R=.522) ; p<.05$. Here, $\mathrm{R}$-squared value is .27 indicating that in the current stage the explanatory variables can explain only $27 \%$ of the variance in dependent variable. Regression results show that Age found to be highly significant at $1 \%$ level of significance. The coefficient of Age being positive, it can be concluded that given the other things, SFP would increase with increase in age of the entrepreneurs. Regression model 2 and 3 shows entrepreneur's Experience is found to be statistically significant and its coefficient is negative $\left(-.283^{* * *},-.247^{*}\right)$. These results were not line with the traditional literature. According to Peake and Marshall (2009) the reason for this is that most firms struggle during their initial earlier years of operation, which may not allow the experience of the entrepreneur to make a positive impact on the firm performance from an empirical stand point. Traditional experience in terms of age, maturity and life experience would be expected to positively impact the firm performance, but modern studies say that management experience is necessary to increase the performance of the firm. For example, if an entrepreneur who has experience in the technology industry but decides to launch a restaurant, than the start up experience he/she gained in the technology industry may not be helpful or useful at all in the restaurant performance. As shown in regression model 2 and 3 entrepreneurs Education is positive and significant $\left(414^{* * *}, 457^{* * * *)}\right.$. The coefficient of being positive, it can be concluded that given the other things, SFP would increase with increase in education of the entrepreneurs.

In Model 2, along with control variables, network size, density and centrality were added. While controlling for the demographic variables, the results showed a significant improvement of overall multivariate relationship $(R=0.788 ; p<0.001)$. The linear 
Table 3 Results of Hierarchical Regression models

\begin{tabular}{|c|c|c|c|}
\hline \multicolumn{4}{|c|}{ Subjective firm performance } \\
\hline \multirow[t]{2}{*}{ Variables } & Model 1 & Model 2 & Model 3 \\
\hline & Beta Sig VIF & Beta Sig VIF & Beta Sig VIF \\
\hline Gender & .167 .3331 .188 & .137 .3221 .305 & .041 .7641 .470 \\
\hline Age & $.615^{* * *} .0041 .820$ & $.575^{* * *} .0022 .067$ & $.640^{* * *} .0012 .129$ \\
\hline Experience & -.210 .2241 .179 & $-.283^{* *} .0451 .292$ & $-.247^{*} .0631 .315$ \\
\hline Education & -.264 .2281 .899 & $414^{* *} .0201 .997$ & $457^{* * *} .0082 .085$ \\
\hline Network size & & $-.316^{* * *} .0031 .579$ & $-.538 * * * .0042 .404$ \\
\hline Density & & $.393 * * .0221 .867$ & $.455^{* * *} .0071 .945$ \\
\hline Centrality & & $.409^{* * *} .0081 .463$ & $.388^{* *} .0301 .659$ \\
\hline Competitive network & & & .122 .4411 .985 \\
\hline Supportive network & & & .252 .1502 .353 \\
\hline $\mathrm{F}$ & $2.815^{* *}$ & $6.306^{* * *}$ & $6.275^{* * *}$ \\
\hline Multiple R & .522 & .788 & .833 \\
\hline $\mathrm{R}$ square & .273 & 620 & 693 \\
\hline Adjusted $\mathrm{R}$ square & .176 & .522 & .583 \\
\hline R square change & .273 & .348 & .073 \\
\hline
\end{tabular}

Source: Author's own calculation

Notes: *** Correlation is significant at the 0.01 level

${ }^{* *}$ Correlation is significant at the 0.05 level

*Correlation is significant at the 0.10 level

combinations of age, entrepreneurial experience, educational level, network size, density and centrality accounted for R-squared .62 which indicated that around $62 \%$ of the total variance in the dependent measure. After controlling the effect of demographic variables, a significant $(\mathrm{R}$ square change $=0.348 ; p<0.001$ ) degree of variance was explained by addition of network size, density and centrality.

In Model 3, along with Model 1 and Model 2 variables, and by adding competitive networks and supportive network, the result that was obtained, showed a significant improvement in the overall multivariate relationship $(R=0.833 ; p<0.001)$ and the coefficient of determination R-squared has also improved. It is .69 which indicated that around $69 \%$ of variance in firm performance is explained by the independent variables. A significant R square change of $.073 p<0.001$ was observed. The results are discussed in relation to the individual hypotheses.

Hypotheses1A proposed that network size has an impact on subjective firm performance. As shown in regression model 2 and 3 of Table 3, do not support hypothesis 1A. But the regression results (Table 3$)$ show a negative $\left(-.316^{* * * *},-.538^{* * * *}\right)$ and highly significant relation. This happens because the total number of contacts of an entrepreneur increases but that also reduces efficiency in performance. There may be problems related to co-ordination, communication and decision making when the number of relationship increases which also ends up hindering performance.

Hypothesis $1 \mathrm{~B}$ suggested that density of the network has an impact on subjective firm performance. As shown in model 2 and 3 of Table 3, density of network has a significant and positive impact on firm performance $\left(.393^{* *}, .455^{* * * *}\right)$. Therefore, the results support the hypotheses1B.

Hypothesis $1 \mathrm{C}$ stated that network centrality has an impact on subjective firm performance. As shown in model 2 and 3 of Table 3, centrality of network has a significant 
and positive impact on firm performance $\left(.409^{* * * *}, 388^{* * *}\right)$. Therefore, the results support the hypotheses1C.

Hypothesis 2A and 2B argued that Competitive network and Supportive network has an impact on subjective firm performance. As shown in the regression model 3 of Table 3 , the results does not support $\mathrm{H} 2 \mathrm{~A}$ and $\mathrm{H} 2 \mathrm{~B}$ that supportive and competition might not increase the performance.

\section{Conclusion}

The purpose for this examination was to explore the effect of enterprenurial networking on firm performance. The different measurements of systems have been contemplated and their association with subjective firm execution have been analyzed.

On the basis of primary data collected in the Kamrup District, this study acknowledges that out of four (gender, age, experience and education) demographic control variables age and education of the entrepreneurs is important for firm performance, which is similar to the entrepreneurial behaviour of small firms across the globe. From the results of the main effects of entrepreneurial networks, it can be concluded that network density and centrality have a positive impact on firm performance. High level of density increases the closeness and high level of centrality increases the quickness in quality of resources and information. However, the regional uniqueness that surfaced in the study is that in case of network size, competition and supportive network don't play a significant role in increase in firm performance.

Finally, the investigation must make reference to some confinement regarding this examination. It has been restricted to just a single area with the state of Assam and it was directed on a constrained sample of little firms, so taking a large sample such as an inter-district variations could be considered in future. Also, the Taguchi based orthogonal array design will be implemented to find which factors affects more on the response variable. (Dar and Anuradha 2018a, 2018b).

\section{Suggestions and future scope}

From the results obtained in this study and keeping in mind the limitations of it, the following issues could be explored.

- In the present study findings point out the significant and positive impact of network density and centrality. As observed above, high level of density increases the closeness and high level of centrality increases the quickness in quality of resources and information. These two features of networks can therefore play a critical role for Small Medium Enterprises and new Start-Ups globally as they go a long way in removing information asymmetries and thereby providing a solution for their betterment.

- Based on the literature accessed, five dimensions have only been tested in regard to entrepreneurial networks. Researchers can examine other dimensions affecting firm performances with extensive investigation.

- Besides, the current study was conducted from subjective measures of performances and it could also be conducted with greater focus towards objective measures of performances. 
- Future research needs to focus on larger cross section of entrepreneurs and more diversified random sampling to verify the findings of the current study.

- Qualitative surveys on a larger sample of cases are needed to strengthen results.

- It would be interesting to study, in future research, how the relationships between subjective and objective measures affect performances. This is of great significance to policy recommendations.

\section{Endnotes}

1 "Building Entrepreneurial Networks", National Commission on Entrepreneurship. Available from https://www.inc.com/encyclopedia/entrepreneurial-networks. December 2001.

${ }^{2}$ Small firms, Small scale Industries and small enterprises are used as synonyms in the present studyNotes: As per the MSMED Act, 2006, small enterprises in India are firms with an investment of '25 Lakhs to 5 Crores' in plant and machinery in the manufacturing sector and of '10 Lakhs to 2 Crores' in equipment in the service sector.

${ }^{3}$ What Ails The Northeast: An Enquiry Into The Economic FactorsSreeradha Datta, Associate Fellow

${ }^{4}$ Economic Survey of Assam, 2016-2017.

${ }^{5}$ In this study External actor refers to persons or organizations

${ }^{6}$ Figure1 is given after the reference list.

${ }^{7}$ Baseline Survey of Minority Concentrated DistrictsDistrict Report kamrup Study Commissioned by Ministry of Minority Affairs Government of India

${ }^{8}$ All items were measured with Likert-like scale with each item showing acceptable reliability withCronbach's alpha values above the recommended threshold (Huck,2000)

${ }^{9} \alpha \geq 0.9$ Excellent $7 \leq \alpha<0.9$ Good0.6 $\leq \alpha<0.7$ Acceptable $0.5 \leq \alpha<0.6$ Poor $\alpha<0.5$ UnacceptableCronbach's (alpha) is used to estimate of the reliability of a psychometric test. Cronbach LJ (1951). "Coefficient alpha and the internal structure of tests"; Psychometrika 16 (4): 297-334.

${ }^{10}$ Hierarchical Models are: "A type of linear regression models in which the observations fall into hierarchical or completely nested levels. Hierarchical Models are a type of Multilevel Models."Hierarchical regression "is the practice of building successive linear regression models, each adding more predictors. For example, one common practice is to start by adding only demographic control variables to the model in one step. In the next model, you can add predictors of interest, to see if they predict the DV above and beyond the effect of the controls. You're actually building separate but related models in each step. But SPSS has a nice function where it will compare the models, and actually test if successive models fit better than previous ones. So hierarchical regression is really a series of regular old OLS regression models-nothing fancy, really." Accessed from the Link Below https://www.theanalysisfactor.com/confusing-statistical-term-4-hierarchical-regression-vs-hierarchical-model/

${ }^{11}$ Calculating, Interpreting, and Reporting Cronbach's Alpha Reliability Coefficient for Likert-Type Scales Gliem, Joseph A. and Gliem, Rosemary R 2003.

${ }^{12}$ VIF: Exceed 3 then we may probably have multicollinearityExceed 5 then we are very likely to have multicollinearity.Tolerance: Below 3 then we may probably have multicollinearityBelow 5 then we are very likely to have multicollinearity.

${ }^{13}$ The $\mathrm{R}$ value indicates the multiple correlation coefficient between all the entered independent variables and the dependent variable. 


\section{Abbreviations}

MSME: Micro Small and Medium Enterprise; SFP: Subjective Firm performance; SMEs: Small and medium enterprises; SMP: Subjective Measures of performance; SSI: Small Scale Industries; VIF: Value Inflation Factors

\section{Acknowledgements}

Both the authors completed this paper solely. There are no other contributors to be listed.

\section{Funding}

The author has no research funding to be declared.

\section{Availability of data and materials}

The datasets generated during the current study are not publicly available; Survey data will be shared after acceptance of the paper and it will be available from the first author on reasonable request.

\section{Authors' contributions}

MD and NG designed the study. MD developed the methodology, collected the data performed the analysis and wrote the manuscript. NG framed the survey questionnaire, conclusion, References formatting and editing sections. Both authors read and approved the final manuscript.

\section{Competing interests}

The author declares that there is no competing interest.

\section{Publisher's Note}

Springer Nature remains neutral with regard to jurisdictional claims in published maps and institutional affiliations.

\section{Author details}

${ }^{1}$ Research Scholar, Department of Economics, Gauhati University, Guwahati, Assam, India. ${ }^{2}$ Associate Professor, Department of Economics, Gauhati University, Guwahati, Assam, India.

Received: 22 June 2018 Accepted: 26 November 2018

Published online: 04 January 2019

\section{References}

Aldrich, H., \& Zimmer, C. (1986). Entrepreneurship through social networks. In The art and science of entrepreneurship (pp. 3-23). Cambridge, MA: Ballinger Retrieved from https:/scholar.google.co.in/scholar?hl=en\&as_sdt=0\%2C5\&q=Aldrich\%2C+H. $\% 2 \mathrm{C}$ +\%26+Zimmer\%2C+C.+\%281986\%29.+Entrepreneurship+through+social+networks.+In+The+art+and+science+of tentrepreneurship+\%28pp.+3\%E2\%80\%93+.

Banker, R. D., Potter, G., \& Srinivasan, D. (2000). An empirical investigation of an incentive plan that includes nonfinancial performance measures. The accounting review, 75(1), 65-92 https://doi.org/10.2308/accr.2000.75.1.65.

Batjargal, B. (2000). Social capital and entrepreneurial performance in Russia: A panel study. Working Paper Number 352 , December. https://doi.org/10.2139/ssrn.258200

Bhattacharyya, A., \& Ahmad, M. U. (2010). Managing the Network: The Case of a Micro-Enterprise. The Journal of Business Perspective Vision, 14(1-2), 85-92 http://www.sagepublications.com https://doi.org/10.1177/097226291001400109.

Birley, S., Cromie, S., \& Myers, A. (1991). Entrepreneurial networks: their emergence in Ireland and overseas. International Small Business Journal, 9(4), 56 https://doi.org/10.1177/026624269100900404.

Capelleras, J. L., \& Rabetino, R. (2008). Individual, organizational and environmental determinants of new firm employment growth: evidence from Latin America. International Entrepreneurship and Management Journal, 4(1), 79-99. Retrieved from https://link.springer.com/article/10.1007/s11365-006-0030-z and https://scholar.google.co.in/scholar?hl=en\&as_sdt= $0 \% 2 \mathrm{C} 5 \& \mathrm{q}=10 \% 09$ Capelleras\%2C+J.+L.\%2C+\%26+Rabetino\%2C+R.+\%282008\%29.+Individual\%2C+organizational+and +environmental+determinants+of+new+firm+employment+growth\% $99 .+\& b t n G=$

Combs, J. G., Russell Crook, T., \& Shook, C. L. (2005). The dimensionality of organizational performance and its implications for strategic management research. In Research methodology in strategy and management (pp. 259-286). Emerald Group Publishing Limited. Retrieved from https://www.emeraldinsight.com/doi/abs/10.1016/S1479-8387\%2805\%2902011-4 https://scholar.google.co.in/scholar?hl=en\&as_sdt=0\%2C5\&q=12.\%09Combs\%2C+J.+G.\%2C+Russell+Crook\%2C+T.\%2C $+\% 26+$ Shook\%2C+C.+L.+\%282005\% 29 .+The+dimensionality+of+organizational+performance+and+its+imp.

Dar, A. A., \& Anuradha, N. (2018a). An Application of Taguchi L9 Method in Black Scholes Model for European Call Option International Journal of Entrepreneurship. Retrieved from https://www.abacademies.org/articles/an-application-of-taguchi19-method-in-black-scholes-model-for-european-call-option-7040.html. https://scholar.google.co.in/scholar?hl=en\&as_sdt= $0 \% 2 \mathrm{C} 5 \& \mathrm{q}=18 . \% 09 \mathrm{Dar} \% 2 \mathrm{C}+\mathrm{A} .+\mathrm{A} . \% 2 \mathrm{C}+\% 26+$ Anuradha\%2C+N.+\%282018a\%29.+An+Application+of+Taguchi+L9+Method +in+Black+Scholes+Model+for+European+Call+Option.+International+.

Dar, A., \& Anuradha, N. (2018b). Use of orthogonal arrays and design of experiment via Taguchi L9 method in probability of default. Accounting, 4(3), 113-122. https://doi.org/10.5267/j.ac.2017.11.001.

Das, K. (1996). Flexibly together: surviving and growing in a garment cluster, Ahmedabad, India. The Journal of Entrepreneurship, 5(2), 153-177 https://doi.org/10.1177/097135579600500201.

Dawes, J. (1999). The relationship between subjective and objective company performance measures in market orientation research: further empirical evidence (Vol. 10, pp. 65-75). Marketing bulletin-department of marketing Massey University Retrieved from https:/www.researchgate.net/publication/265455042_The_Relationship_between_Subjective_and_ Objective_Company_Performance_Measures_in_Market_Orientation_Research_Further_Empirical_Evidence.

Donckels, R., \& Lambrecht, J. (1995). Networks and small business growth: an explanatory model. Small Business Economics, 7(4), 273-289 Retrieved from https://www.jstor.org/stable/40228809?seq=1\#page_scan_tab_contents. 
Drucker, P. F. (1990). The emerging theory of manufacturing. Harvard Business Review, 68(3), 94-102 https://elibrary.ru/item. asp?id=1529806.

Dubini, P., \& Aldrich, H. (1991). Personal and extended networks are central to the entrepreneurial process. Journal of Business Venturing, 6(5), 305-313. https://doi.org/10.1016/0883-9026(91)90021-5.

Farina, V. (2008). Network embeddedness, specialization choices and performance in investment banking industry. https://doi. org/10.2139/ssin. 1578798

Frazier, B. J. (2000). In ) (Ed.), The influence of network characteristics on information access, marketing competence and perceptions of performance in small rural businesses Unpublished, Doctoral Dissertation, Michigan State University.

Gliem, J. A., \& Gliem, R. R. (2003). Calculating, interpreting, and reporting Cronbach's alpha reliability coefficient for Likert-type scales. Midwest Research-to-Practice Conference in Adult, Continuing, and Community. Education Retrieved from https:// scholarworks.iupui.edu/handle/1805/344.

Gulati, R., Nohria, N., \& Zaheer, A. (2000). Strategic Networks. Strategic Management Journal, 21(3), 203-215 https://doi.org/10. 1002/(SICI)1097-0266(200003)21:3<203::AID-SMJ102>3.0.CO;2-K.

Hanneman, R. A., \& Riddle, M. (2005). Introduction to social network methods. Riverside, CA: University of California Retrieved from https://scholar.google.co.in/scholar?hl=en\&as_sdt=0\%2C5\&q=+Hanneman\%2C+R.A.\%2C+\%26+Riddle\%2C+M.+ \%282005\%29.+Introduction+to+social+network+methods+.Riverside\%2C+CA\%3A+University+of+California.+\&btnG=.

Hansen, G. S., \& Wernerfelt, B. (1989). Determinants of firm performance: The relative importance of economic and organizational factors. Strategic management journal, 10(5), 399-411 https://doi.org/10.1002/smj.4250100502.

Hite, J. M., \& Hesterly, W. S. (2001). The evolution of firm networks: From emergence to early growth of the firm. Strategic management journal, 22(3), 275-286 https://doi.org/10.1002/smj.156.

Hoffman, C. C., Nathan, B. R., \& Holden, L. M. (1991). A comparison of validation criteria: objective versus subjective performance measures and self-versus supervisor ratings. Personnel Psychology, 44(3), 601-618 https://doi.org/10.1111/j. 1744-6570.1991.tb02405.x.

Huta, V. (2014). When to Use Hierarchical Linear Modeling. The Quantitative Methods for Psychology, 10(1), 13-28. https://doi. org/10.20982/tgmp.10.1.p013.

Ittner, C. D., Larcker, D. F., \& Meyer, M. W. (2003). Subjectivity and the weighting of performance measures: Evidence from a balanced scorecard. The accounting review, 78(3), 725-758 https://doi.org/10.2308/accr.2003.78.3.725.

Johannisson, B., Alexanderson, O., Nowicki, K., \& Senneseth, K. (1994). Beyond anarchy and organization: entrepreneurs in contextual networks. Entrepreneurship \& Regional Development, 6(4), 329-356 https://doi.org/10.1080/08985629400000020.

Li, X., \& Zhang, S. (2007). Entrepreneurial networks, firm resources, and performance. Paper presented at first Asian conference on family business at international school of business (ISB). Available online at: www.isb.edu/.../ ManagingFamilyBusinessinChina.pdf

McNair, C. J., \& Mosconi, W. (1987). Measuring Performance in an Advanced Manufacturing Environment [2]. Strategic. Finance, 69(1), $28 \mathrm{https} / / /$ search.proquest.com/openview/9e317ed6c04df5ccfcb1f251e8b6872f/1?cbl=48426\&pq-origsite= gscholar.

Peake, W. O., \& Marshall, M. I. (2009). Does experience determine performance? A meta-analysis on the experience-performance relationship. Agricultural and Applied Economics Association. Retrieved from https://ageconsearch.umn.edu/bitstream/ 49275/2/613108.pdf. https://scholar.google.co.in/scholar?hl=en\&as_sdt=0\%2C5\&q=+45.\%09Peake\%2C+W.+0.\%2C+\%26 +Marshall\%2C+M.+1.+\%282009\%29.+Does+experience+determine+performance\%3F+A+metaanalysis+ on+the +experience-performance+relationship.+Agricultural+and+Applied+Economics+Association.+\&btnG=.

Prajapati, K., \& Biswas, S. N. (2011). Effect of entrepreneur network and entrepreneur self-efficacy on subjective performance: a study of handicraft and handloom cluster. The Journal of Entrepreneurship, 20(2), 227-247 https://doi.org/10.1177/ 097135571102000204.

Richard, P. J., Devinney, T. M., Yip, G. S., \& Johnson, G. (2009). Measuring organizational performance: Towards methodological best practice. Journal of management, 35(3), 718-804 https://doi.org/10.1177/0149206308330560.

\section{Submit your manuscript to a SpringerOpen ${ }^{\circ}$ journal and benefit from:}

- Convenient online submission

Rigorous peer review

- Open access: articles freely available online

- High visibility within the field

- Retaining the copyright to your article

Submit your next manuscript at $\boldsymbol{s p r i n g e r o p e n . c o m ~}$ 